\title{
High-throughput method to test antimicrobial gels against a multispecies oral biofilm
}

2 Kanchana Chathoth $^{1^{*}}$, Bénédicte Martin ${ }^{1}$, Martine Bonnaure-Mallet $^{1,2}$ and Christine Baysse ${ }^{1}$

$3 \quad *$ Corresponding author: kanchana-nandanan.chathoth@univ-rennes1.fr

$4 \quad{ }^{1}$ University Rennes 1, NUMECAN INSERM U1241, CIMIAD F-35043 Rennes, France

$5 \quad{ }^{2}$ CHU Pontchaillou, Rennes

6 Keywords: oral biofilm, antibacterial gels, Porphyromonas gingivalis, Treponema denticola,

7 Streptococcus gordonii. oxygen

\section{ABSTRACT}

Periodontitis, characterized by the damage of the periodontium can eventually lead to tooth loss. Moreover, severe forms of periodontitis are associated with several systemic disorders. The evolution of the disease is linked to the pathogenic switch of the oral microbiota comprising of commensal colonizers and anaerobic pathogens. Treatment with antimicrobial gels has the potential to help eradicate periodontal pathogens. Testing antibacterial gels against in vitro biofilm models is complicated. Recovery of detached and sessile bacteria from in vitro biofilms treated with gel formulations using conventional methods (microtiter plates, $\mu$-slides, flow cells etc.,) may prove arduous. To overcome this challenge, we optimised a simple method using the principle of the Calgary Biofilm Device (CBD) for testing antimicrobial gels against multispecies oral biofilms. First, we established three-species oral biofilms consisting of two periodontal pathogens (Porphyromonas gingivalis, Treponema denticola) and a primary colonizer of the dental plaque (Streptococcus gordonii) on the surface of pegs. Next, a protocol to test gels against oral biofilms was implemented using commercially available gels with different active products.

22 This method enables the analysis of the composition of biofilm and detached/planktonic cells to

23 measure the effect of topical gel formulations/antibacterial gels for the treatment of periodontitis.

24 However, the method is not restricted to oral biofilms and can be adapted for other biofilm-

25 related studies.

\section{INTRODUCTION}

27 Periodontitis is a polymicrobial chronic inflammatory disease of the periodontium caused by the accumulation of dental plaque (Pihlstrom et al., 2005). It is regarded as the second most common 
disease worldwide, with severe forms affecting up to 10 to $15 \%$ of adults (Petersen and Ogawa, 2012) resulting in tooth loss. Many studies have reported an association of severe periodontitis with several systemic disorders (Beukers et al., 2017; Bui et al., 2019; Graves et al., 2019; Hujoel et al., 2003; Koziel et al., 2014; López, 2008; Preshaw et al., 2012) and oral malodor (Lee et al., 2003; Yaegaki, 2008). Therefore, periodontal diseases are a major socio-economic concern.

Metagenomics analysis of the microbial community in the human subgingival plaque has revealed the presence of over 500 species (Ai et al., 2017). This oral biofilm formation is initiated by early colonizers that recognize receptors in the acquired pellicle that coats the enamel of the tooth. These early colonizers consist mainly of facultative anaerobic Gram-positive bacteria such as Streptococcus spp. and Actinomyces spp. In the oral health-associated biofilm, these Grampositive cocci and rods predominate. Change in dominant species with an increase of putative pathogens like Porphyromonas gingivalis, Treponema denticola, Tannerella forsythia and Prevotella intermedia results in dysbiosis and thus periodontal disease (Kolenbrander et al., 2002; Meuric et al., 2017). The mechanism behind the shift from health-associated oral microbiota to periodontal pathogens is not clearly understood. This pathogenic shift is probably linked to the changes in the composition and/or virulence of microbiota as a result of changes in the oral environment (Pöllänen et al., 2013). In our recent review (Chathoth et al., 2020), we hypothesize that an excess of iron and the resultant ROS generated in presence of the peroxygenic streptococci may be one of the contributors for dysbiosis. Therefore, it is of interest to be able to access changes in biofilm composition in response to a treatment.

Antimicrobial agents in the form of gel formulations are a promising delivery system for the treatment of periodontitis via topical administration. The advantages include the ease of use, increased retention time at the site of application and controlled drug release. Several authors have demonstrated the effectiveness of gel formulations in reducing microbial content or plaque

54 index (Figueiredo de Almeida Gomes et al., 2006; Noyan et al., 1997; Paquette et al., 1997; Sauvêtre et al., 1993) in human, animal-based or in vitro studies. Similar improvement in probing depth and/or bleeding was reported (Esposito et al., 1996; Graça et al., 1997) on use of gel

57 formulations alone or in conjunction with other modes of treatment. There is an increasing 
2002), poly(lactic-co-glycolic acid)/hyaluronic acid (Noda et al., 2018), cranberry juice concentrate (H.R. et al., 2017) in gel formulations. The non-toxic properties of such compounds combined with the advantages of gel as a delivery system is continuously explored as a treatment strategy.

63 Conventional methods for growing biofilms in vitro (microtiter plates, $\mu$-slides, flow cells etc.) pose several difficulties in testing antimicrobial gels against biofilms. The biofilm and the treatment ought to be in the same place. Owing to the viscosity and adhesive nature of gels, the recovery of detached and sessile bacteria for assessment after treatment gets complicated. The Minimum Biofilm Elimination Concentration $\left(\mathrm{MBEC}^{\mathrm{TM}}\right.$ ) Assay System (formerly the Calgary Biofilm Device) was previously challenged with gel-based products to assess their bactericidal activity on mono-species biofilm (Martineau and Dosch, 2007; Santos et al., 2016). Hence, a method adapted to both gel-based products and polymicrobial biofilms, and capable of deciphering the behaviour of each species in response to the treatment was needed. In this study, we combined a method using the principle of the Calgary Biofilm Device (CBD) (Ceri et al., 1999) and a new medium for oral bacteria (Martin et al., 2018) for testing antimicrobial gels against multispecies oral biofilms. This protocol using a lid with pegs and a 96-well microtiter plate was adapted to establish three-species oral biofilms on the surface of the pegs. The three species consisted of two key periodontal pathogens $P$. gingivalis, $T$. denticola and a primary colonizer of the dental plaque, S. gordonii. The basis for the selection of these microorganisms was the species-specific co-aggregation of $S$. gordonii with $P$. gingivalis (Lamont and Hajishengallis, 2015) and the syntrophy and synergy between $P$. gingivalis and $T$. denticola (Meuric et al., 2013; Tan et al., 2014; Zhu et al., 2013). Moreover, P. gingivalis and T. denticola, co-exist in deep periodontal pockets (Kigure et al., 1995; Kumawat et al., 2016) and are associated with severe forms of periodontitis. S. gordonii is a peroxygenic bacteria and a glutathione producer that can also influence the pathogenic switch of the oral subgingival biofilm (Chathoth et al., 2020). Most importantly, we use saliva-coated pegs to grow the three-species biofilm in vitro to mimic the dental plaque developing initially at the root of teeth. This biofilm was realised in the MMBC-3 medium which allows the growth of the three bacterial species (Martin et al., 2018). The method was adapted to analyse the composition of the biofilm and detached planktonic growth in order to test topical gel formulations/antibacterial gels against oral biofilms for the treatment of periodontitis. 
The method was challenged with two commercial gels, Hyalugel ${ }^{\circledR}$-ADO (Ricerfarma, Milan, Italy) and blue ${ }^{\circledR} \mathrm{m}$ oral gel (blue ${ }^{\circledR} \mathrm{m}$ Europe B.V., Netherlands). Hyalugel ${ }^{\circledR}$-ADO mainly consists of hyaluronic acid $(0.2 \%)$ which is a major component of the extracellular matrix of the skin and plays a vital role in skin repair (Neuman et al., 2015). Hyaluronic acid showed an antibacterial activity against both planktonic bacteria and biofilms (Ardizzoni et al., 2011; Binshabaib et al., 2020; Eick et al., 2013; Pirnazar et al., 1999). The main ingredients of the blue ${ }^{\circledR} \mathrm{m}$ oral gel are sodium perborate $(1.72 \%)$ and lactoferrin $(0.2 \%)$. Sodium perborate acts as the oxygen donor that can be lethal to the anaerobic periodontal pathogens. Lactoferrin has antimicrobial, antiinflammatory and anti-carcinogenic properties and also acts as an iron chelator (Wang et al., 2019). Previous reports have demonstrated that blue ${ }^{\circledR} \mathrm{m}$ oral gel reduced $P$. gingivalis planktonic growth (Deliberador et al., 2020) and also showed antiplaque and anti-gingivitis efficacy in the form of a toothpaste (Cunha et al., 2019).

\section{METHODS}

\section{Strains and media}

Strains of Streptococcus gordonii Challis DL1 (Chen et al., 2004), Porphyromonas gingivalis TDC60 (Watanabe et al., 2011) and Treponema denticola ATCC35405 (Chan et al., 1993) were used for the study. The cultures of S. gordonii and P. gingivalis were grown in MMBC-3 (Medium for Mixed Bacterial Community), with $\mathrm{FeSO}_{4} \cdot 7 \mathrm{H}_{2} \mathrm{O}_{2}$ (Sigma-Aldrich) at $8 \mu \mathrm{M}$ and protoporphyrin IX (PPIX, Sigma-Aldrich) at $0.08 \mu \mathrm{M}$ as the iron source (Martin et al., 2018). T. denticola was initially grown in NOS spirochete medium (Leschine and Canale-Parola, 1980) and further sub-cultured in MMBC-3 supplemented with $\mathrm{FeSO}_{4} \cdot 7 \mathrm{H}_{2} \mathrm{O}_{2}(8 \mu \mathrm{M})$ and PPIX $(0.08 \mu \mathrm{M})$. All three micro-organisms were grown in anaerobic condition at $37^{\circ} \mathrm{C}$ in an anaerobic chamber (MACS 500, Don Whitley Scientific, United Kingdom) with $10 \%$ v:v $\mathrm{H}_{2}, 10 \%$ v:v $\mathrm{CO}_{2}$ and $80 \% \mathrm{v}: \mathrm{v} \mathrm{N}_{2}$.

\section{Growth and treatment of the biofilm}

The protocol for the growth and treatment of the biofilm is detailed in Figure 1. As the first step, $200 \mu$ of saliva (Pool Human Donors, MyBioSource), filtered $(0.20 \mu \mathrm{m})$ and diluted twice in sterile distilled water, was added into the Nunc ${ }^{\mathrm{TM}}$ Nunclon $^{\mathrm{TM}}$ 96-well tissue culture microtiter plates. The lid with pegs (Nunc-TSP, polystyrene) was placed over the microtiter plate and 
incubated in saliva for 30 minutes. Next, the saliva was replaced by $200 \mu 1$ of inoculum consisting of $S$. gordonii $\left(\mathrm{OD}_{600 \mathrm{~nm}}: 0.05\right), P$. gingivalis $\left(\mathrm{OD}_{600 \mathrm{~nm}}: 0.1\right)$ and $T$. denticola $\left(\mathrm{OD}_{600 \mathrm{~nm}}: 0.1\right)$ in a new microtiter plate. The lid with pegs was placed on the microtiter plate ensuring that the pegs were immersed in the inoculum. This set-up was incubated in anaerobic conditions for 6 hours. Meanwhile, the challenge plate consisting of the two gel treatments and MMBC-3 was prepared in a new microtiter plate in aerobic condition by adding $150 \mu$ l of each of the treatments and the medium in individual wells of the 96-well microtiter plate with the aid of 1 $\mathrm{ml}$ syringes. The 6-hour three-species biofilms or adherent cells present on the surface of the pegs were subjected to either MMBC-3 or Hyalugel ${ }^{\circledR}-\mathrm{ADO}$ or blue ${ }^{\circledR} \mathrm{m}$ oral gel for 1 hour in anaerobic condition. After the 1-hour treatment, the pegs were carefully lifted from the challenge plate and further incubated in the microtiter wells containing $200 \mu 1$ of MMBC-3 for 24 hours in anaerobic conditions. After the 24-hour incubation, the 96-well microtiter plate comprised of bacteria that detached (as a consequence of either the treatment or biofilm formation on the pegs) and proliferated in planktonic form in the well. The pegs consisted of biofilm formed either due to the bacteria remaining on its surface post-treatment or the biofilm build-up due to the planktonic bacteria in the wells of the microtiter plate. Both samples (detached/planktonic cells and biofilm) are representative of the effectiveness of the treatment.

The detached/planktonic cells were collected from the microtiter plate and the biofilm were collected from the surface of the pegs by sonication $(30 \mathrm{~min}$ ) and were quantified by qPCR. 6 pegs ( 2 per condition) were broken with the help of pliers and stained with Syto ${ }^{\circledR} 9$ for visualization using confocal laser microscopy.

\section{Confocal microscopy and imaging}

Treated and untreated biofilm-containing pegs after a 24-hour incubation in MMBC-3 were subjected to microscopic imaging after staining with $5 \mu \mathrm{M}$ of Syto ${ }^{\circledR} 9$ green-fluorescent nucleic acid stain (Invitrogen, ThermoFisher Scientific) diluted in PBS. Briefly, 6 pegs were broken anaerobically from the lid with the help of sterile pliers and were placed in a microtiter plate containing the stain $(200 \mu \mathrm{l})$ for $20 \mathrm{~min}$. They were further transferred to Syto ${ }^{\circledR} 9$ stain-filled (200 $\mu 1) \mu$-slides ( 8 chambered coverslip, ibiTreat, Ibidi) anaerobically. The biofilm on the surface of the stained pegs was then observed in situ with a Leica TCS-SP5 confocal laser scanning microscope (Leica Microsystems, Wetzlar, Germany). An HC PL Apo 10X, 0.4 NA oil 
149

immersion objective lens was used for image capture and a numerical zoom of 2 was applied. The 488-nm UV diode and a 485 to 500-nm band-pass emission filter were used to detect all bacteria stained with Syto ${ }^{\circledR} 9$. Biofilm stacks $(123 \times 123 \mu \mathrm{m})$ acquired at $1 \mu \mathrm{m}$ intervals were scanned with a line average of 2. Also, zoomed images were captured using HC PL Apo 63X, 1.4 NA oil immersion objective lens with a numerical zoom of 5.05.

Leica software (LAS AF V.2.2.1) was used for microscope piloting and image acquisition. Analysis of images based on Syto ${ }^{\circledR} 9$ was performed in ImageJ software V1.43m (National Institute of Health, USA) to obtain the maximum z-projection of the images.

\section{Quantification of bacteria by qPCR}

The bacteria, consisting of $S$. gordonii, $P$. gingivalis and $T$. denticola, in the initial inoculum and the planktonic/detached cells collected after treatment were centrifuged $\left(8000 \mathrm{xg}, 20^{\circ} \mathrm{C}, 10 \mathrm{~min}\right)$ and the pellets were resuspended in $150 \mu \mathrm{l}$ of Lysis buffer $(20 \mathrm{mg} / \mathrm{ml}$ lysozyme in $20 \mathrm{mM}$ Tris$\mathrm{HCl}, 2$ mM EDTA, $1.2 \%$ Triton X, PBS, pH 8). Biofilms were collected in $150 \mu$ Lysis buffer by sonication for $30 \mathrm{~min}$ using a water bath sonicator (Ultrasonic cleaner). The biofilm collected from 3 pegs from the same condition (treated or untreated) were pooled together to increase the sample volume and to compensate for the low biofilm surface area on the pegs (approximately 44 $\mathrm{mm}^{2}$ per peg) (Harrison et al., 2010; MBEC assay procedural manual, version 2.0, Innovotech). All samples were subjected to DNA extraction using QIAamp DNA Mini kit (Qiagen) according to the manufacturer's instructions with slight modification i.e. the lysis using proteinase $\mathrm{K}$ was performed overnight.

Quantitative PCR was performed in a total reaction volume of $12.5 \mu$ l containing $6 \mu$ Takyon ${ }^{\mathrm{TM}}$ Low Rox SYBR ${ }^{\circledR}$ MasterMix dTTP Blue (Eurogentec), $0.5 \mu \mathrm{l}$ of each primer $(5 \mu \mathrm{M})$, and $1 \mu \mathrm{l}$ of the sample. Amplification of the extracted DNA template was performed in QuantStudio ${ }^{\mathrm{TM}} 7$ Flex Real-Time PCR System (Applied Biosystems) by initial incubation of 2 min at $55^{\circ} \mathrm{C}$ and 10 min at $95^{\circ} \mathrm{C}$, followed by 40 cycles of $15 \mathrm{sec}$ at $95^{\circ} \mathrm{C}$ and $1 \mathrm{~min}$ at $60^{\circ} \mathrm{C}$. A melt curve stage was performed consisting of $15 \mathrm{sec}$ at $95^{\circ} \mathrm{C}$ followed by a temperature gradient from $60^{\circ} \mathrm{C}$ to $95^{\circ} \mathrm{C}$ with fluorescence measured in an increment of $1^{\circ} \mathrm{C}$ every $15 \mathrm{sec}$.

The concentrations of the DNA samples were determined in comparison with the defined concentrations of DNA standards set in the range of 0.0001 to $10 \mathrm{ng}$ with purified genomic DNA 
178

179

180

181

182

183

184

185

186

187

188

189

190

191

192

193

194

195

196

197

198

199

200

201

202

203

204

205

206

from each of the three species. Primers used were specific to each species targeting the $16 \mathrm{~S}$ ribosomal RNA taking into account specific genome weights $\left(2.58 \times 10^{-6} \mathrm{ng}\right.$ for $P$. gingivalis, $3.12 \times 10^{-6} \mathrm{ng}$ for T. denticola and $2.41 \times 10^{-6} \mathrm{ng}$ for S. gordonii) (Ammann et al., 2013; Martin et al., 2017). The primers used in this study are listed in Table 1.

\section{Statistical analysis}

All the experiments were done with 3 biological and 3 technical replicates. Statistical analysis was performed using the two-tailed unpaired student t-test and a p-value of less than 0.05 was considered statistically significant.

\section{RESULTS}

\section{Establishment of the three-species oral biofilm on the peg-lid using MMBC-3 medium}

The method of using Nunc-TSP lids with pegs allowed the formation and growth of the threespecies oral biofilm on the surface of the pegs. Using this method, biofilm that formed on the peg surface after 31 hours ( 6 hours of growth prior to treatment +1 hour of treatment +24 hours of post-treatment growth, see methods and Figure 1) in MMBC-3 medium were quantified by qPCR (Figure 3A) and visualized by confocal fluorescent microscopy (Figure 2A and D). The microscopic images are representative of the total biofilm density and do not differentiate individual species. However, it enables the visualization of clusters of bacteria (Figure 2D) when zoomed. Additionally, the planktonic or detached bacteria in the 96-well microtiter plate were also quantified by qPCR (Figure 3A). The concentration of each species (S. gordonii, $P$. gingivalis and T. denticola) in the biofilm (Figure 3B) and planktonic/ detached condition (Figure 3C) were also measured.

The three-species biofilm quantified on the surface of the untreated pegs ( 3 pegs pooled together) is $2.08 \times 10^{7} \mathrm{CFU} / \mathrm{ml}$ (Figure $3 \mathrm{~A}$ ). This value corresponds to $1.5 \times 10^{5} \mathrm{CFU} / \mathrm{mm}^{2}$ (as the growth area per peg is $44 \mathrm{~mm}^{2}$ ). Martin et al., (2018), in another study using the same species and medium reported biofilm formation of approximately $1 \times 10^{10} \mathrm{CFU} / \mathrm{ml}$ in conventional $\mu$-slides. This value corresponds to $1 \times 10^{8} \mathrm{CFU} / \mathrm{mm}^{2}$ (as the growth area of each well in a $\mu$-slides is 100 $\mathrm{mm}^{2}$ ). The concentration of the biofilm (in CFU/ $\mathrm{mm}^{2}$ ) on the surface of the pegs is 650 times lesser than the concentration of biofilm on $\mu$-slides. This difference is as expected since the pegs and $\mu$-slides vary in structure and surface area. Also, conventional methods (like $\mu$-slides) for 
biofilm formation pose the concerns of aggregation linked to sedimentation of bacteria in the wells. However, this concern can be disregarded in the case of peg-lids due to its protruding topology. Even though the concentration of bacteria in the biofilm on the surface of the pegs is less in comparison to conventional methods, it is still detectable by qPCR (in the species level) (Figure 3B) and can also be visualized by confocal microscopy (Figure 2A and D).

At the species level, the biofilm on the peg surface contains $99.2 \% \mathrm{~S}$. gordonii, $0.5 \% \mathrm{P}$. gingivalis and $0.4 \%$ T. denticola (Figure 4A). The composition of each species in the biofilm in conventional $\mu$-slides (Martin et al., 2018) is approximately $98.1 \% \mathrm{~S}$. gordonii, $1.3 \% \mathrm{P}$. gingivalis and $0.6 \%$ T. denticola. This ensures that even though the concentration of the biofilm is far less on the peg surface in comparison to $\mu$-slides, it does not have a major effect on the overall composition (or ratio) of individual species for identical inocula. S. gordonii is seen to always predominate the population in the case of both peg-lids and $\mu$-slides. This predominance of $S$. gordonii is also observed in the case of planktonic growth (Figure 4B). Further, on considering the sum of the bacteria in the biofilm and the detached (or planktonic) form as the total bacteria, we observe that a majority of bacteria remain in the planktonic form for all three species (Table 2).

This method thus enabled the establishment of an oral biofilm model consisting of a facultative anaerobic commensal and two anaerobic pathogens on the surface of the pegs. It further allowed the analysis of the composition and quantification of each species in the biofilm and planktonic form. The use of the parameters described above will permit the comparison between various antibacterial gels against an oral biofilm model.

\section{Effect of antibacterial gels against a 6-hour three-species oral biofilm model}

Next, in order to validate this method (Figure 1) on gel formulations, we tested the effect of two commercially available gels, namely, Hyalugel ${ }^{\circledR}$-ADO and blue ${ }^{\circledR} \mathrm{m}$ oral gel on the 3 -species 6hour biofilm established using MMBC-3 on the surface of the pegs. The two gels have comparable viscosities, $35000-60000 \mathrm{cP}$ for Hyalugel ${ }^{\circledR}$-ADO, and $25000-50000 \mathrm{cP}$ for blue ${ }^{\circledR} \mathrm{m}$ oral gel, as given by respective manufacturers. No gel without potential active compound was available to discriminate between the effect of viscosity and the effect of the active compound. Therefore, the method used evaluated both parameters against oral biofilm and enabled the comparison of gels with comparable viscosity. 
The method allowed us to assess the number of sessile and planktonic bacteria remaining after treatment. We could also identify the most impacted species amongst a mixed biofilm. Focusing on the two gels used to implement the method, the concentration of the total bacteria was significantly reduced from $4.11 \times 10^{9} \mathrm{CFU} / \mathrm{ml}$ to $5.15 \times 10^{6} \mathrm{CFU} / \mathrm{ml}$ after treatment of the 6-hour three-species biofilm with Hyalugel ${ }^{\circledR}-\mathrm{ADO}$ in comparison to MMBC-3 (Figure 3A). The decrease is evident in the concentration of bacteria in the biofilm as well as the concentration of bacteria in the detached/planktonic form. A similar trend was observed in the case of blue ${ }^{\circledR} \mathrm{m}$ oral gel with total number of bacteria decreasing from $4.11 \times 10^{9} \mathrm{CFU} / \mathrm{ml}$ to $1.50 \times 10^{7} \mathrm{CFU} / \mathrm{ml}$ when compared to MMBC-3. The treatment with blue ${ }^{\circledR} \mathrm{m}$ oral gel showed a decrease in the concentration of bacteria in the biofilm but an increase in detached/planktonic cells when compared to the treatment with Hyalugel ${ }^{\circledR}$-ADO (Figure 3A). The blue ${ }^{\circledR}$ m oral gel showed greater efficiency in decreasing the concentration of bacteria in the biofilm when compared to Hyalugel $^{\circledR}$-ADO (Figure 3A). This decrease in biofilm concentration from MMBC-3 to Hyalugel $^{\circledR}$-ADO to blue ${ }^{\circledR} \mathrm{m}$ oral gel is also evident in the microscopic images (Figure $2 \mathrm{~A}, \mathrm{~B}, \mathrm{C}$ ).

The method used was efficient to monitor the variations in the concentration of each species after treatment. In the present protocol used to implement the method, the concentration of bacteria in the biofilm decreased significantly in the case of $S$. gordonii and T. denticola from MMBC-3 to Hyalugel $^{\circledR}$-ADO to blue ${ }^{\circledR}$ m oral gel while no effect of the two gels was seen on $P$. gingivalis (Figure 3B). Alternately, the concentration of $S$. gordonii and P. gingivalis in the detached/planktonic form, post-treatment with Hyaluge ${ }^{\circledR}$-ADO decreased significantly in comparison to MMBC-3 (Figure 3C). No effect of Hyalugel ${ }^{\circledR}$-ADO in comparison to MMBC-3 was observed on the concentration of $T$. denticola in the detached/planktonic form. In contrast, 260 denticola significantly increased in comparison to MMBC-3, while that of S. gordonii decreased. 261 Also, the treatment with blue ${ }^{\circledR} \mathrm{m}$ oral gel showed a higher concentration of all three species in the 262 detached/planktonic form when compared to treatment with Hyalugel ${ }^{\circledR}$-ADO.

263 Therefore, this method permitted the analysis of the effect of treatment on the composition of the 264 biofilm and planktonic cultures. The percentage of $S$. gordonii in the antibacterial gel-treated 265 (Hyalugel ${ }^{\circledR}$-ADO and blue ${ }^{\circledR}$ m oral gel) biofilms decreased in comparison to untreated biofilm 
(Figure 4A). However, the ratio of the three species in the biofilm remained similar between the two treatments. The percentage of detached/planktonic $S$. gordonii decreased from untreated to treated biofilms, the least percentage being in the case of blue ${ }^{\circledR} \mathrm{m}$ oral gel (Figure 4B). As a result, the percentage of the planktonic form of $P$. gingivalis and $T$. denticola increased posttreatment when compared to untreated biofilms. The percentage of planktonic $P$. gingivalis is higher in the case of blue ${ }^{\circledR} \mathrm{m}$ oral gel-treated biofilms while the percentage of planktonic $T$. denticola is similar between the two treatments.

Finally, using this method, it is possible to evaluate the effect of treatment on the distribution between sessile and planktonic cells for each species. The species-wise percentage of biofilm and detached planktonic cells post-treatment with the gels in comparison to MMBC-3 was evaluated, where $100 \%$ constituted the sum of the percentages of bacteria in the biofilm and the detached planktonic form. The percentage of biofilm post-treatment with Hyalugel ${ }^{\circledR}$-ADO in comparison to MMBC-3, was higher in the case of $S$. gordonii and $P$. gingivalis while lower in the case of $T$. denticola. Treatment with blue ${ }^{\circledR} \mathrm{m}$ oral gel only modified and increased the percentage of $S$. gordonii in the biofilm in comparison to untreated biofilms. The percentage of planktonic bacteria was significantly reduced in the case of $S$. gordonii between untreated and treated biofilms (from $99.6 \%$ for MMBC-3 to $96.4 \%$ for blue ${ }^{\circledR}$ m oral gel to $84.8 \%$ for Hyalugel $^{\circledR}$ ADO). For planktonic form of $P$. gingivalis a reduction was observed when Hyalugel ${ }^{\circledR}$-ADOtreated biofilms were compared to MMBC-3 (from 65.0 \% for MMBC-3 to $48.4 \%$ for Hyalugel $^{\circledR}$-ADO). However, an increase in the percentage of planktonic form of $P$. gingivalis was observed in the case of blue ${ }^{\circledR} \mathrm{m}$ oral gel-treatment as compared to Hyalugel ${ }^{\circledR}-\mathrm{ADO}$ and MMBC-3. Also, an increase in the percentage of planktonic form of $T$. denticola was seen after gel treatment (from $87.2 \%$ for MMBC-3 to $94.3 \%$ for to Hyalugel ${ }^{\circledR}$-ADO to $99.3 \%$ for blue ${ }^{\circledR}$ m oral gel).

In short, the method was therefore efficient to determine the specific effect of both treatments on the oral biofilm: Hyalugel ${ }^{\circledR}-\mathrm{ADO}$ (containing $0.2 \%$ hyaluronic acid), reduced the planktonic growth of $S$. gordonii and $P$. gingivalis while it did not affect planktonic growth of $T$. denticola. This is in agreement with previously reported results (Ardizzoni et al., 2011; Pirnazar et al., 1999). Further, Hyalugel ${ }^{\circledR}$-ADO reduced the biofilm formation of $S$. gordonii and T. denticola but did not affect the biofilm growth of $P$. gingivalis when compared to untreated biofilms. 
297

298

299

300

301

302

303

304

305

306

307

308

309

310

311

312

313

314

315

316

317

318

319

320

321

322

323

324

325

326

blue ${ }^{\circledR} \mathrm{m}$ oral gel in comparison to untreated biofilms, reduced the overall growth of $S$. gordonii, increased the detached planktonic growth of $P$. gingivalis and $T$. denticola and reduced the biofilm growth of $S$. gordonii and T. denticola.

\section{DISCUSSION}

Traditional methods for the development of biofilms (like microtiter plates, $\mu$-slides, Ludin chambers etc.) can pose difficulties in testing the antimicrobial effect of gels against biofilms. In this study, we developed a high throughput method to test antibacterial gels against multispecies oral biofilm. This method uses the principle of the Calgary Biofilm Device to grow biofilms and was adapted for the growth of multispecies biofilm consisting of oral bacteria. We used the MMBC-3 (Martin et al., 2018) as the growth medium especially designed for the growth of the three species used in this study. We use an apparatus/arrangement consisting of a 96-well microtiter plate and a lid with pegs. With the help of the microtiter plate, biofilms are established on the surface of the pegs. These biofilms are further challenged with antibacterial gels to test the effect of these gels against the oral biofilm model. Our method resolves the concerns posed by conventional methods by growing the biofilm on pegs while preparing the treatment in a microtiter plate. The separation of the treatment from the biofilm is thus not needed. We have devised a means of analyzing the effect of the treatment by further incubating the treated biofilm in a fresh microtiter plate containing medium (MMBC-3). Here, we assess the ability of the bacteria in the treated biofilm to further grow as biofilm (on the peg-surface) or planktonic culture (in the microtiter plate) in the MMBC-3 medium. Briefly, our method nullifies the need for separation of bacteria (either in biofilm or planktonic form) from the treatment/gel while it also allows the analysis of each species in the biofilm and planktonic form post-treatment. It is known that gels have an inherent shear force due to their viscous and adhesive nature which can result in the removal of bacteria from the surface of the pegs. In this study, to test the method, we compare the efficiency of two commercially available gels (with comparable viscosity) in biofilm reduction as a combined effect of its inherent shear force and its respective active compounds and against untreated biofilms.

The reduction in the biofilm in comparison to untreated biofilms may be due to the combined effect of the active antimicrobial compound (hyaluronic acid, sodium perborate or lactoferrin) and the viscous nature of gels. It cannot be excluded that since the 6-hour biofilm is scanty, its 
removal from the peg surface is enabled by the inherent viscous/adhesive nature of the gel. The method allowed us to compare two treatments with comparable viscosity. Here, blue ${ }^{\circledR} \mathrm{m}$ oral gel induced higher concentration of the three species as planktonic cells while lower S. gordonii and T. denticola concentrations in the biofilm, compared to Hyalugel ${ }^{\circledR}-$ ADO. The difference may be due to active compounds as both gels have comparable viscosity. The oxygen donor present in blue ${ }^{\circledR} \mathrm{m}$ oral gel may have an effect on the obligate anaerobe $T$. denticola or boost the peroxygenic activity of $S$. gordonii and change the biofilm behaviour (Chathoth et al., 2020). Lactoferrin of blue ${ }^{\circledR} \mathrm{m}$ oral gel can reduce the initial attachment of S. gordonii (Arslan et al., 2009). This may explain the decrease in $S$. gordonii in blue ${ }^{\circledR} \mathrm{m}$ oral gel-treated biofilms.

Our method demonstrated the ability of both gels in the reduction of the overall biofilm growth in comparison to untreated biofilm. They were especially effective in reducing $S$. gordonii and $T$. denticola in the biofilm. S. gordonii along with 16 other genera, has been previously classified under 'signatures of dysbiosis' due to its predominance in patients with periodontitis and edentulism (Hunter et al., 2016). Also, its role in co-aggregation and metabolic interactions with other periodontal pathogens is well-known (Hajishengallis and Lamont, 2016; Sakanaka et al., 2015). On the other hand, T. denticola, a member of the red complex, is known for its metabolic symbiosis, co-aggregation and synergy with the keystone pathogen $P$. gingivalis (Ito et al., 2010; Meuric et al., 2013; Ng et al., 2019). Hence, the reduction of S. gordonii and T. denticola in the oral biofilm model with a single treatment for 1 hour with either of the two gels is indeed a promising result. Both the gels have the potential of preventing oral dysbiosis and co-aggregation of periodontal pathogens. Hence multiple exposures/treatments per day with either of the two gels is likely to show better efficacy in the reduction of the dental plaque.

\section{CONCLUSION}

Antimicrobial gels are a promising treatment and can additionally be used as dressings and fillers, particularly in periodontal pockets, where the pathogenic oral biofilm resides. This study describes the method of using peg-lids for testing antimicrobial gels on multispecies biofilms. It offers the possibility of simultaneous testing of multiple conditions with reproducible cell density (Goeres et al., 2005). It eliminates concerns due to sedimentation of bacteria (which is possible in the case of conventional methods). The method presented in this study has been optimized for the growth and development of oral biofilms in an iron-controlled medium. The effect of gels against 
the oral biofilms is measured by analyzing the concentration of bacteria in the biofilm or planktonic form across treatments in comparison to the untreated biofilms. Another parameter that is assessed is the ratio of each species in the biofilm and planktonic form. Further, the ratio of the bacteria in the biofilm to the planktonic form is also evaluated to understand the effect of the treatment in comparison to untreated condition. Finally, the treated biofilms after incubation in MMBC-3 for 24 hours is also subjected to confocal laser microscopy to visualize the effect of the treatments on the biofilms. However, the number of the live and dead bacteria in the biofilm and planktonic growth after the treatments can be assessed to further optimize the method (Harrison et al., 2007). Therefore, we will know if the antibacterial gels are bacteriostatic or bactericidal in action. Assays with various times of incubation of the biofilms prior to treatment can also be performed to model different pathogenic states. This method can be further adapted for other studies like testing antibacterial compounds (other than gels) against biofilms. Besides, biofilms other than oral biofilms can also be grown and studied using this method.

\section{FUNDING SOURCE}

This work was supported by the Conseil Régional de Bretagne, France (F3/48 CPER), the Fondation "Les Gueules Cassées/Sourire Quand Même" and the Federative Research Structure Biosit (Rennes).

\section{AUTHOR STATEMENT}

The study was designed by $\mathrm{KC}, \mathrm{BM}$ and $\mathrm{CB}$; experiments were performed by $\mathrm{KC}$; the data was analysed by $\mathrm{KC}, \mathrm{BM}$ and $\mathrm{CB}$; the manuscript was written and edited by $\mathrm{KC}, \mathrm{BM}, \mathrm{MBM}$ and $\mathrm{CB}$.

\section{DECLARATION OF COMPETING INTEREST}

The authors declare no competing interests.

\section{ACKNOWLEDGEMENTS}

We thank blue ${ }^{\circledR} \mathrm{m}$ Europe B.V., Netherlands for sending us their product- blue ${ }^{\circledR} \mathrm{m}$ oral gel, for this study and for product-related information. We also thank the manufacturer of Hyalugel ${ }^{\circledR}$ ADO, Ricerfarma (Milan, Italy) and the distributer, Laboratoire COOPER, Melun, France, for providing the product-related information. Our sincere gratitude to the Microscopy Rennes Imaging Center (Biosit) for their technical assistance for the microscopy experiments. 


\section{REFERENCES}

386

387

388

389

390

391

392

393

394

395

396

397

398

399

400

401

402

403

404

405

406

407

408

409

410

411

412

413

414

415

416

417

418

419

Ai, D., Huang, R., Wen, J., Li, C., Zhu, J., and Xia, L.C. (2017). Integrated metagenomic data analysis demonstrates that a loss of diversity in oral microbiota is associated with periodontitis. BMC Genomics 18, 1041. DOI: 10.1186/s12864-016-3254-5.

Ammann, T.W., Bostanci, N., Belibasakis, G.N., and Thurnheer, T. (2013). Validation of a quantitative real-time PCR assay and comparison with fluorescence microscopy and selective agar plate counting for species-specific quantification of an in vitro subgingival biofilm model. J Periodontal Res. 48, 517-526. DOI: 10.1111/jre.12034.

Ardizzoni, A., Neglia, R.G., Baschieri, M.C., Cermelli, C., Caratozzolo, M., Righi, E., Palmieri, B., and Blasi, E. (2011). Influence of hyaluronic acid on bacterial and fungal species, including clinically relevant opportunistic pathogens. J Mater Sci Mater Med. 22, 2329-2338. DOI: 10.1007/s10856-011-4408-2.

Arslan, S.Y., Leung, K.P., and Wu, C.D. (2009). The effect of lactoferrin on oral bacterial attachment. Oral Microbiol Immunol. 24, 411-416. DOI: 10.1111/j.1399-302X.2009.00537.x.

Beukers, N.G.F.M., Heijden, G.J.M.G. van der, Wijk, A.J. van, and Loos, B.G. (2017). Periodontitis is an independent risk indicator for atherosclerotic cardiovascular diseases among 60174 participants in a large dental school in the Netherlands. J Epidemiol Community Health 71, 37-42. DOI: 10.1136/jech-2015-206745.

Binshabaib, M., Aabed, K., Alotaibi, F., Alwaqid, M., Alfraidy, A., and Alharthi, S. (2020). Antimicrobial efficacy of $0.8 \%$ Hyaluronic Acid and $0.2 \%$ Chlorhexidine against Porphyromonas gingivalis strains: An in-vitro study. Pak J Med Sci 36, 111-114. DOI: 10.12669/pjms.36.2.1456.

Bui, F.Q., Almeida-da-Silva, C.L.C., Huynh, B., Trinh, A., Liu, J., Woodward, J., Asadi, H., and Ojcius, D.M. (2019). Association between periodontal pathogens and systemic disease. Biomed J. 42, 27-35. DOI: 10.1016/j.bj.2018.12.001.

Ceri, H., Olson, M.E., Stremick, C., Read, R.R., Morck, D., and Buret, A. (1999). The Calgary Biofilm Device: New Technology for Rapid Determination of Antibiotic Susceptibilities of Bacterial Biofilms. J Clin Microbiol. 37, 1771-1776. DOI: 10.1128/JCM.37.6.1771-1776.1999.

Chan, E.C.S., Siboo, R., Keng, T., Psarra, N., Hurley, R., Cheng, S.-L., and Iugovaz, I. (1993). Treponema denticola (ex Brumpt 1925) sp. nov., nom. rev., and Identification of New Spirochete Isolates from Periodontal Pockets. Int J Syst Bacteriol. 43, 196-203. DOI: 10.1099/00207713-432-196.

Chathoth, K., Martin, B., Cornelis, P., Yvenou, S., Bonnaure-Mallet, M., and Baysse, C. (2020). The events that may contribute to subgingival dysbiosis: a focus on the interplay between iron, sulfide and oxygen. FEMS Microbiol Lett 367(14). DOI: 10.1093/femsle/fnaa100. 
420

421

422

423

424

425

426

427

428

429

430

431

432

433

434

435

436

437

438

Chen, C.C., Teng, L.J., and Chang, T.C. (2004). Identification of Clinically Relevant Viridans Group Streptococci by Sequence Analysis of the 16S-23S Ribosomal DNA Spacer Region. J Clin Microbiol 42, 2651-2657. DOI: 10.1128/JCM.42.6.2651-2657.2004.

Cunha, E.J., Auersvald, C.M., Deliberador, T.M., Gonzaga, C.C., Esteban Florez, F.L., Correr, G.M., and Storrer, C.L.M. (2019). Effects of Active Oxygen Toothpaste in Supragingival Biofilm Reduction: A Randomized Controlled Clinical Trial. Int J Dent. 2019:3938214. DOI: $10.1155 / 2019 / 3938214$.

Deliberador, T.M., Weiss, S.G., Rychuv, F., Cordeiro, G., Cate, M.C.L.T., Leonardi, L., Brancher, J.A., and Scariot, R. (2020). Comparative Analysis in Vitro of the Application of blue ${ }^{\circledR} \mathrm{m}$ Oral Gel versus Chlorhexidine on Porphyromonas gingivalis: A Pilot Study. AiM 10, 194-201. DOI: 10.4236/aim.2020.104015.

Eick, S., Renatus, A., Heinicke, M., Pfister, W., Stratul, S.-I., and Jentsch, H. (2013). Hyaluronic Acid as an Adjunct After Scaling and Root Planing: A Prospective Randomized Clinical Trial. J Periodontol. 84, 941-949. DOI: 10.1902/jop.2012.120269.

Esposito, E., Carotta, V., Scabbia, A., Trombelli, L., D’Antona, P., Menegatti, E., and Nastruzzi, C. (1996). Comparative analysis of tetracycline-containing dental gels: Poloxamer- and monoglyceride-based formulations. Int. J. Pharm. 142, 9-23. https://doi.org/10.1016/03785173(96)04649-2.

Figueiredo de Almeida Gomes, B.P., Vianna, M.E., Sena, N.T., Zaia, A.A., Ferraz, C.C.R., and de Souza Filho, F.J. (2006). In vitro evaluation of the antimicrobial activity of calcium hydroxide combined with chlorhexidine gel used as intracanal medicament. Oral Surg Oral Med Oral Pathol Oral Radiol Endod. 102, 544-550. DOI: 10.1016/j.tripleo.2006.04.010.

Goeres, D.M., Loetterle, L.R., Hamilton, M.A., Murga, R., Kirby, D.W., and Donlan, R.M. (2005). Statistical assessment of a laboratory method for growing biofilms. Microbiology 151, 757-762. DOI: 10.1099/mic.0.27709-0.

Graça, M.A., Watts, T.L.P., Wilson, R.F., and Palmer, R.M. (1997). A randomized controlled trial of a $2 \%$ minocycline gel as an adjunct to non-surgical periodontal treatment, using a design with multiple matching criteria. J Clin Periodontol. 24, 249-253. DOI: 10.1111/j.1600051x.1997.tb01838.x.

Graves, D.T., Corrêa, J.D., and Silva, T.A. (2019). The Oral Microbiota Is Modified by Systemic Diseases. J Dent Res 98, 148-156. DOI: 10.1177/0022034518805739.

Hajishengallis, G., and Lamont, R.J. (2016). Dancing with the Stars: how Choreographed Bacterial Interactions Dictate Nososymbiocity and Give Rise to Keystone Pathogens, Accessory Pathogens, and Pathobionts. Trends Microbiol 24, 477-489. DOI: 10.1016/j.tim.2016.02.010.

Harrison, J.J., Ceri, H., Yerly, J., Rabiei, M., Hu, Y., Martinuzzi, R., and Turner, R.J. (2007). Metal Ions May Suppress or Enhance Cellular Differentiation in Candida albicans and Candida tropicalis Biofilms. Appl. Environ. Microbiol. 73, 4940-4949. DOI: 10.1128/AEM.02711-06. 
Harrison, J.J., Stremick, C.A., Turner, R.J., Allan, N.D., Olson, M.E., and Ceri, H. (2010). Microtiter susceptibility testing of microbes growing on peg lids: a miniaturized biofilm model for high-throughput screening. Nat Protoc. 5, 1236-1254. DOI: 10.1038/nprot.2010.71.

H R, R., Dhamecha, D., Jagwani, S., Patil, D., Hegde, S., Potdar, R., Metgud, R., Jalalpure, S., Roy, S., Jadhav, K., Tiwari, N.K., Koduru, S., Hugar, S., Dodamani, S. (2017). Formulation of thermoreversible gel of cranberry juice concentrate: Evaluation, biocompatibility studies and its antimicrobial activity against periodontal pathogens. Mater Sci Eng C Mater Biol Appl. 75, 1506-1514. DOI: 10.1016/j.msec.2017.03.054.

Hujoel, P.P., Drangsholt, M., Spiekerman, C., and Weiss, N.S. (2003). An Exploration of the Periodontitis-Cancer Association. Annals of Epidemiology 13, 312-316. DOI: 10.1016/s10472797(02)00425-8.

Hunter, M.C., Pozhitkov, A.E., and Noble, P.A. (2016). Microbial signatures of oral dysbiosis, periodontitis and edentulism revealed by Gene Meter methodology. J Microbiol Methods. 131, 85-101. DOI: 10.1016/j.mimet.2016.09.019.

İkinci, G., Şenel, S., Akıncıbay, H., Kaş, S., Erciş, S., Wilson, C.G., and Hıncal, A.A. (2002).

Ito, R., Ishihara, K., Shoji, M., Nakayama, K., and Okuda, K. (2010). Hemagglutinin/Adhesin domains of Porphyromonas gingivalis play key roles in coaggregation with Treponema denticola. FEMS Immunol Med Microbiol 60, 251-260. DOI: 10.1111/j.1574695X.2010.00737.x.

Kigure, T., Saito, A., Seida, K., Yamada, S., Ishihara, K., and Okuda, K. (1995). Distribution of periodontal pocket depths examined by immunohistochemical methods. J Periodontal Res. 30, 332-341. DOI: 10.1111/j.1600-0765.1995.tb01284.x.

Koziel, J., Mydel, P., and Potempa, J. (2014). The Link Between Periodontal Disease and 10.1128/mmbr.66.3.486-505.2002. Rheumatoid Arthritis: An Updated Review. Curr Rheumatol Rep 16. DOI: 10.1007/s11926-0140408-9. of Porphyromonas gingivalis and Treponema denticola in chronic and aggressive periodontitis patients: A comparative polymerase chain reaction study. Contemp Clin Dent 7, 481-486. DOI: 10.4103/0976-237X.194097.

492 Lamont, R.J., and Hajishengallis, G. (2015). Polymicrobial synergy and dysbiosis in 493 inflammatory disease. Trends Mol Med. 21, 172-183. DOI: 10.1016/j.molmed.2014.11.004. 
494

Lee, C.-H., Kho, H.-S., Chung, S.-C., Lee, S.-W., and Kim, Y.-K. (2003). The relationship between volatile sulfur compounds and major halitosis-inducing factors. J. Periodontol. 74, 3237. DOI: 10.1902/jop.2003.74.1.32.

Leschine, S.B., and Canale-Parola, E. (1980). Rifampin as a Selective Agent for Isolation of Oral Spirochetes. J Clin Microbiol., 12(6):792-5. DOI: 10.1128/JCM.12.6.792-795.1980.

López, R. (2008). Periodontal disease and adverse pregnancy outcomes. Evid Based Dent. 9, 48. DOI: 10.1038/sj.ebd.6400581.

Martin, B., Tamanai-Shacoori, Z., Bronsard, J., Ginguené, F., Meuric, V., Mahé, F., and Bonnaure-Mallet, M. (2017). A new mathematical model of bacterial interactions in two-species oral biofilms. PLoS ONE 12, e0173153. DOI: 10.1371/journal.pone.0173153.

Martin, B., Chathoth, K., Ouali, S., Meuric, V., Bonnaure-Mallet, M., and Baysse, C. (2018). New growth media for oral bacteria. J Microbiol Methods. 153, 10-13. DOI: 10.1016/j.mimet.2018.08.013.

Martineau, L., and Dosch, H.-M. (2007). Biofilm reduction by a new burn gel that targets nociception. J Appl Microbiol. 103, 297-304. DOI: 10.1111/j.1365-2672.2006.03249.x.

Meuric, V., Martin, B., Guyodo, H., Rouillon, A., Tamanai $\square$ Shacoori, Z., Barloy $\square$ Hubler, F., and Bonnaure $\square$ Mallet, M. (2013). Treponema denticola improves adhesive capacities of Porphyromonas gingivalis. Mol Oral Microbiol 28, 40-53. DOI: 10.1111/omi.12004.

Meuric, V., Le Gall-David, S., Boyer, E., Acuña-Amador, L., Martin, B., Fong, S.B., BarloyHubler, F., and Bonnaure-Mallet, M. (2017). Signature of Microbial Dysbiosis in Periodontitis. Appl. Environ. Microbiol. 83. DOI: 10.1128/AEM.00462-17.

Neuman, M.G., Nanau, R.M., Oruña-Sanchez, L., and Coto, G. (2015). Hyaluronic Acid and Wound Healing. J Pharm Pharm Sci. 18, 53-60. DOI: 10.18433/j3k89d.

Ng, H.M., Slakeski, N., Butler, C.A., Veith, P.D., Chen, Y.-Y., Liu, S.W., Hoffmann, B., Dashper, S.G., and Reynolds, E.C. (2019). The Role of Treponema denticola Motility in Synergistic Biofilm Formation with Porphyromonas gingivalis. Front. Cell. Infect. Microbiol. 9. DOI: 10.3389/fcimb.2019.00432.

Noda, T., Okuda, T., Mizuno, R., Ozeki, T., and Okamoto, H. (2018). Two-Step SustainedRelease PLGA/Hyaluronic Acid Gel Formulation for Intra-articular Administration. Biol Pharm Bull. 41, 937-943. DOI: 10.1248/bpb.b18-00091.

Noyan, Ü., Yilmaz, S., Kuru, B., Kadir, T., Acar, O., and Büget, E. (1997). A clinical and microbiological evaluation of systemic and local metronidazole delivery in adult periodontitis patients. J Clin Periodontol. 24, 158-165. DOI: 10.1111/j.1600-051x.1997.tb00485.x.

Paquette, D.W., Waters, G.S., Stefanidou, V.L., Lawrence, H.P., Friden, P.M., O’Connor, S.M., Sperati, J.D., Oppenheim, F.G., Hutchens, L.H., and Williams, R.C. (1997). Inhibition of 
experimental gingivitis in beagle dogs with topical salivary histatins. J Clin Periodontol. 24, 216222. DOI: 10.1111/j.1600-051x.1997.tb01834.x.

Petersen, P.E., and Ogawa, H. (2012). The global burden of periodontal disease: towards integration with chronic disease prevention and control: Global periodontal health. Periodontol 2000. 60, 15-39. DOI: 10.1111/j.1600-0757.2011.00425.x.

Pihlstrom, B.L., Michalowicz, B.S., and Johnson, N.W. (2005). Periodontal diseases. Lancet 366, 1809-1820. DOI: 10.1016/S0140-6736(05)67728-8.

536 Pirnazar, P., Wolinsky, L., Nachnani, S., Haake, S., Pilloni, A., and Bernard, G.W. (1999).

537 Bacteriostatic Effects of Hyaluronic Acid. J Periodontol. 70, 370-374. DOI:

538 10.1902/jop.1999.70.4.370.

Pöllänen, M.T., Paino, A., and Ihalin, R. (2013). Environmental Stimuli Shape Biofilm 10.3390/ijms140817221.

543 Taylor, R. (2012). Periodontitis and diabetes: a two-way relationship. Diabetologia 55, 21-31.

544 DOI: $10.1007 / \mathrm{s} 00125-011-2342-\mathrm{y}$.

Sakanaka, A., Kuboniwa, M., Takeuchi, H., Hashino, E., and Amano, A. (2015). ArginineOrnithine Antiporter ArcD Controls Arginine Metabolism and Interspecies Biofilm Development of Streptococcus gordonii. J. Biol. Chem. 290, 21185-21198. DOI: 10.1074/jbc.M115.644401.

Santos, R., Gomes, D., Macedo, H., Barros, D., Tibério, C., Veiga, A.S., Tavares, L., Castanho, M., and Oliveira, M. (2016). Guar gum as a new antimicrobial peptide delivery system against diabetic foot ulcers Staphylococcus aureus isolates. J Med Microbiol. 65, 1092-1099. DOI: 10.1099/jmm.0.000329.

Sauvêtre, E., Glupczynsky, Y., Labbé, M., Yourassowsky, E., Sauvêtre, E., and Pourtois, M.

553 (1993). The effect of clindamycin gel insert in periodontal pockets, as observed on smears and 554 cultures. Infection 21, 245-247. DOI: 10.1007/BF01728900.

Tan, K.H., Seers, C.A., Dashper, S.G., Mitchell, H.L., Pyke, J.S., Meuric, V., Slakeski, N., Cleal, S.M., Chambers, J.L., McConville, M.J., Reynolds, E.C. (2014). Porphyromonas gingivalis and Treponema denticola Exhibit Metabolic Symbioses. PLoS Pathog. 10, e1003955. DOI:

558 10.1371/journal.ppat.1003955.

559 Wang, B., Timilsena, Y.P., Blanch, E., and Adhikari, B. (2019). Lactoferrin: Structure, function, denaturation and digestion. Crit Rev Food Sci Nutr. 59, 580-596. DOI: 10.1080/10408398.2017.1381583. the Bacterium Porphyromonas gingivalis TDC60, Which Causes Periodontal Disease. J Bacteriol 193, 4259-4260. DOI: 10.1128/JB.05269-11. 
Yaegaki, K. (2008). Oral malodorous compounds are periodontally pathogenic and carcinogenic.

Japanese Dental Science Review 44, 100-108. https://doi.org/10.1016/j.jdsr.2008.06.003.

568 Zhu, Y., Dashper, S.G., Chen, Y.-Y., Crawford, S., Slakeski, N., and Reynolds, E.C. (2013).

569 Porphyromonas gingivalis and Treponema denticola Synergistic Polymicrobial Biofilm

570 Development. PLoS ONE 8, e71727. DOI: 10.1371/journal.pone.0071727.

\section{FIGURE LEGENDS:}

573 Figure 1: The process of testing antimicrobial gels on oral biofilms established on the 574 surface of the pegs of the Calgary Biofilm Device. (see methods)

575 Figure 2: Representative microscopic images of the three-species oral biofilm on the surface

of the pegs. Post 1-hour treatment (with MMBC-3, Hyalugel ${ }^{\circledR}-\mathrm{ADO}$ or blue ${ }^{\circledR} \mathrm{m}$ oral gel) of the 6hour biofilms on the surface of the pegs, the pegs were incubated in MMBC-3 for 24 hours. The pegs were further broken from the lid using pliers and stained using Styo ${ }^{\circledR} 9$. The stained pegs were visualized using the Leica TCS-SP5 confocal laser scanning microscope. To compare between the three treatments, maximum z-production of the $\mathrm{Z}$ stack were taken using $10 \mathrm{X}$ oil immersion objective lens and numerical zoom of 2: (A), (B), (C). Magnified images were captured using the $63 \mathrm{X}$ oil immersion objective lens, numerical zoom of 5.05: (D), (E), (F).

Figure 3: qPCR quantification of the number of bacteria (CFU/ml) in the biofilm (collected from the pegs) and in planktonic form (collected from the 96-well microtiter plate). The 6oral gel for 1 hour and further incubated in MMBC-3 for 24 hours. The planktonic cells were collected from the 96-well plate while the biofilm was collected from the pegs and quantified.

(A) Total concentration (CFU/ml) of bacteria (planktonic/detached + biofilm), bacteria in biofilm and bacteria detached or in planktonic form after each treatment. (B) Concentration of each species in the biofilm after each treatment. (C) Concentration of each species in planktonic/ detached cells for each treatment. p-value $<0.05=*$, p-value $<0.01=* *$, p-value $<0.001=* * *$

592 Figure 4: Composition of each species in the biofilms and in the detached/planktonic form

593 post-treatment. Percentage of each species (S. gordonii, P. gingivalis, T. denticola) in the

594 biofilms (A) and in the detached/planktonic form (B) after treatment with either Hyalugel ${ }^{\circledR}$-ADO 595 (grey bars) or blue ${ }^{\circledR} \mathrm{m}$ oral gel (blue bars) in comparison to MMBC-3 (orange bars). The 
596 percentage of each species is mentioned above respective bars. 100\% stands for the sum of the

597 percentages of the three species either in the biofilm or the detached (or planktonic) form.

598

599

600

601

602

603

604

605

606

607

608

609

610

611

612

613

614

615

616

617

618 
Table 1: Species-specific primer sequences used in this study

\begin{tabular}{|l|l|}
\hline \multirow{2}{*}{ Organism } & Sequence $\left(5^{\prime} \rightarrow 3^{\prime}\right)$ \\
\hline \multirow{5}{*}{ Streptococcus gordonii } & F: AAG-CAA-CGC-GAA-GAA-CCT-TA \\
\cline { 2 - 3 } & R: GTC-TCG-CTA-GAG-TGC-CCA-AC \\
\hline \multirow{2}{*}{ Treponema denticola } & F: TGG-GTT-TAA-AGG-GTG-CGT-AG \\
\cline { 2 - 3 } & R: CAA-TCG-GAG-TTC-CTC-GTG-AT \\
\hline \multirow{2}{*}{ F: CGC-GTC-CCA-TTA-GCT-AGT-TG } \\
\cline { 2 - 2 } & R: TTC-TTC-ATT-CAC-ACG-GCG-TC \\
\hline
\end{tabular}

620 
Table 2: Species-wise percentage of biofilm and detached (or planktonic) cells posttreatment with either Hyalugel ${ }^{\circledR}$-ADO or blue ${ }^{\circledR}$ m oral gel in comparison to MMBC-3.

\begin{tabular}{|l|l|l|l|l|l|l|}
\hline & \multicolumn{2}{|l|}{ MMBC-3 } & \multicolumn{2}{l|}{ Hyalugel $^{\circledR}$-ADO } & \multicolumn{2}{l|}{ blue $^{(} \mathrm{m}$ oral gel } \\
\hline & \% biofilm & $\begin{array}{l}\% \\
\text { detached/ } \\
\text { planktonic } \\
\text { cells }\end{array}$ & $\%$ biofilm & $\begin{array}{l}\% \\
\text { detached/ } \\
\text { planktonic } \\
\text { cells }\end{array}$ & $\%$ biofilm & $\begin{array}{l}\text { detached/ } \\
\text { planktonic } \\
\text { cells }\end{array}$ \\
\hline S. gordonii & $0.4 \pm 0.2$ & $99.6 \pm 0.2$ & $15.2 \pm 9.1$ & $84.8 \pm 9.1$ & $3.5 \pm 1.9$ & $96.5 \pm 1.9$ \\
\hline P. gingivalis & $35.0 \pm 13.9$ & $65.0 \pm 13.9$ & $51.6 \pm 22.8$ & $48.4 \pm 22.8$ & $1.2 \pm 1.1$ & $98.8 \pm 1.1$ \\
\hline T. denticola & $12.8 \pm 3.6$ & $87.2 \pm 3.6$ & $5.7 \pm 4.1$ & $94.3 \pm 4.1$ & $0.7 \pm 0.4$ & $99.3 \pm 0.4$ \\
\hline
\end{tabular}

$100 \%$ stands for the sum of the percentages of bacteria in the biofilm and the detached (or

639 planktonic) form.

$640 \%$ Calculation:

641 Percentages of bacteria in the biofilm:

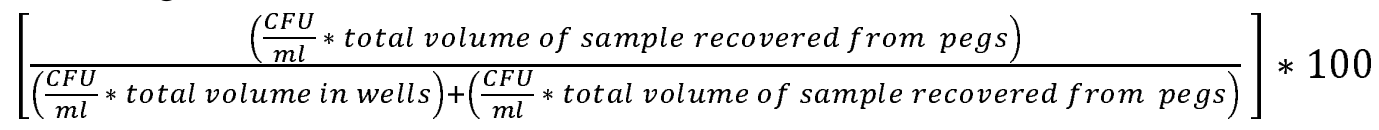

644 Percentages of bacteria in the detached (or planktonic) form: 


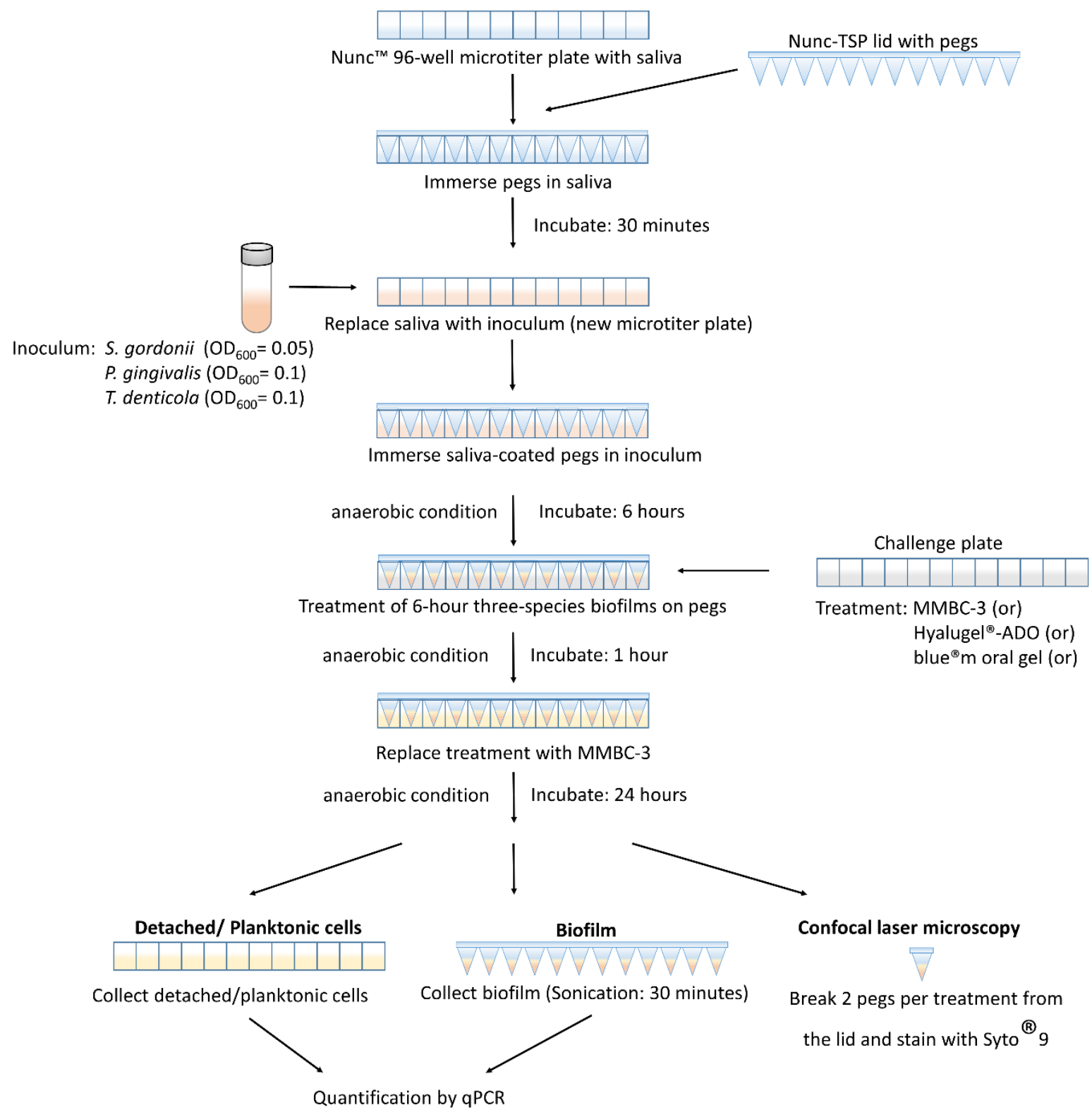

Figure 1 

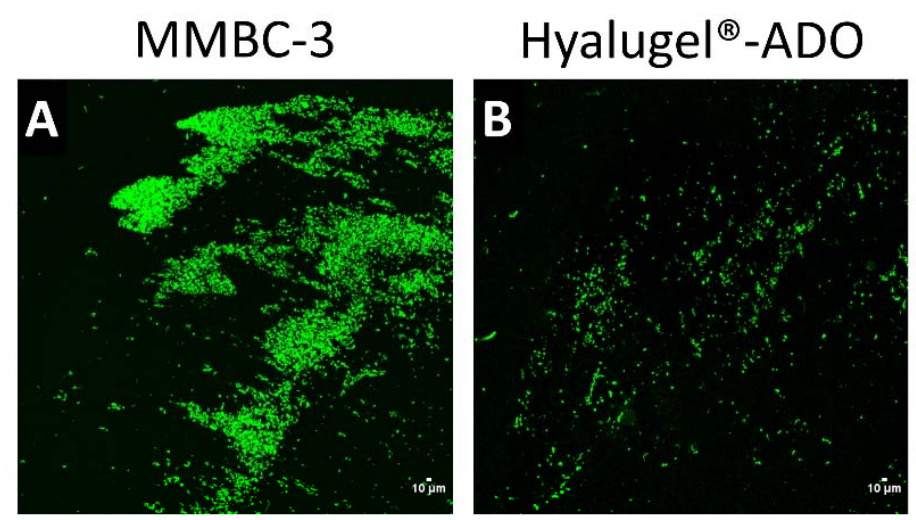

\section{blue ${ }^{\circledR} \mathrm{m}$ oral gel}
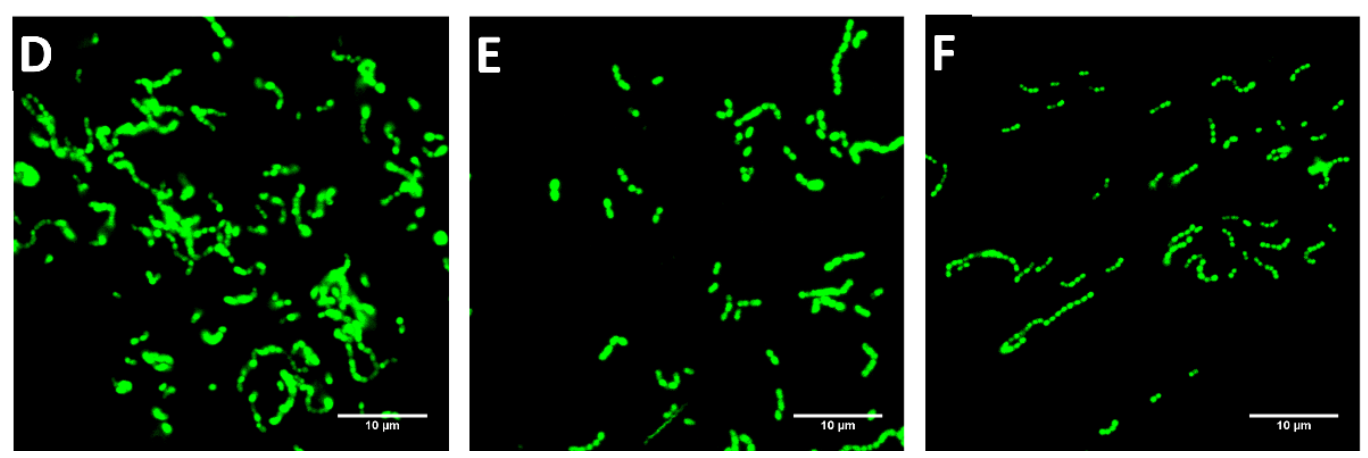

Figure 2 
bioRxiv preprint doi: https://doi.org/10.1101/2020.09.08.287391; this version posted September 8, 2020. The copyright holder for this preprint (which was not certified by peer review) is the author/funder, who has granted bioRxiv a license to display the preprint in perpetuity. It is made available under aCC-BY-NC-ND 4.0 International license.

A

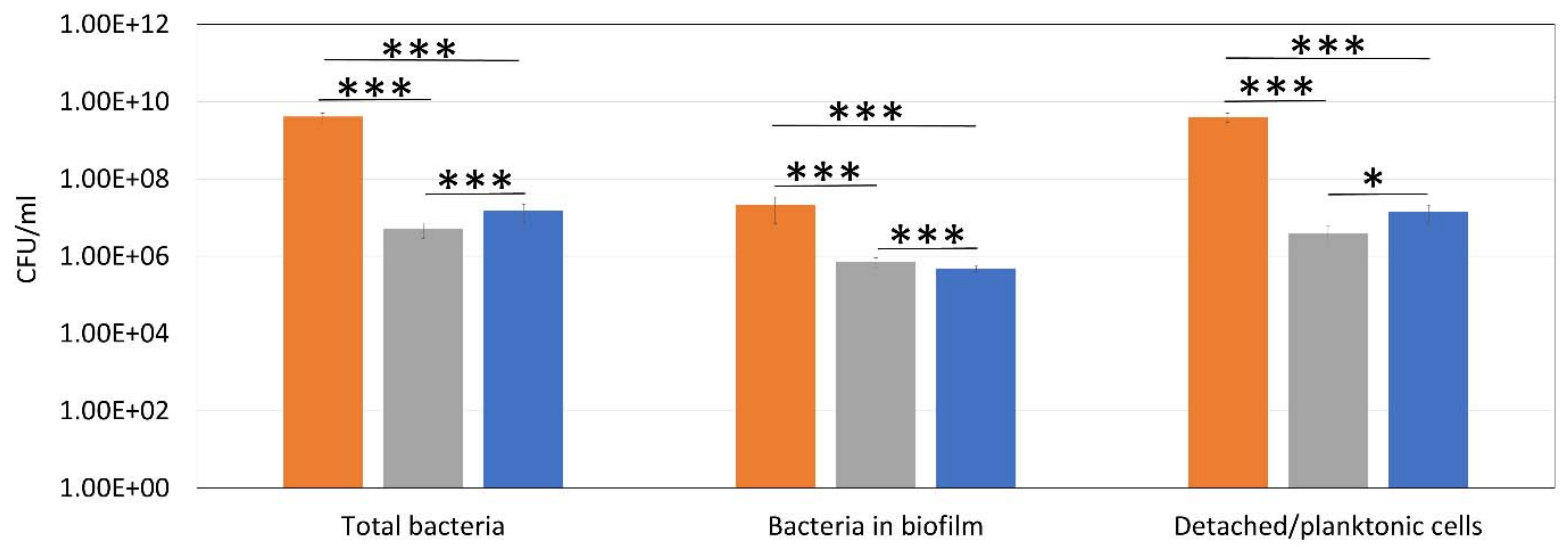

B

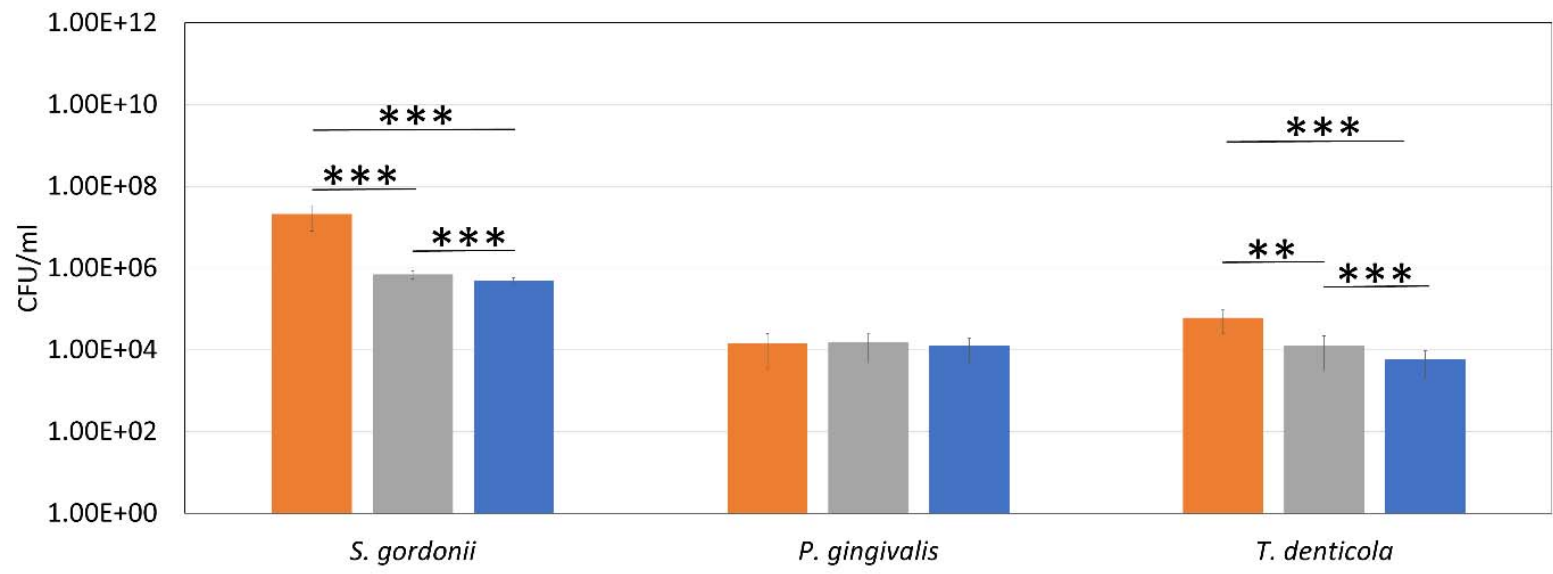

C

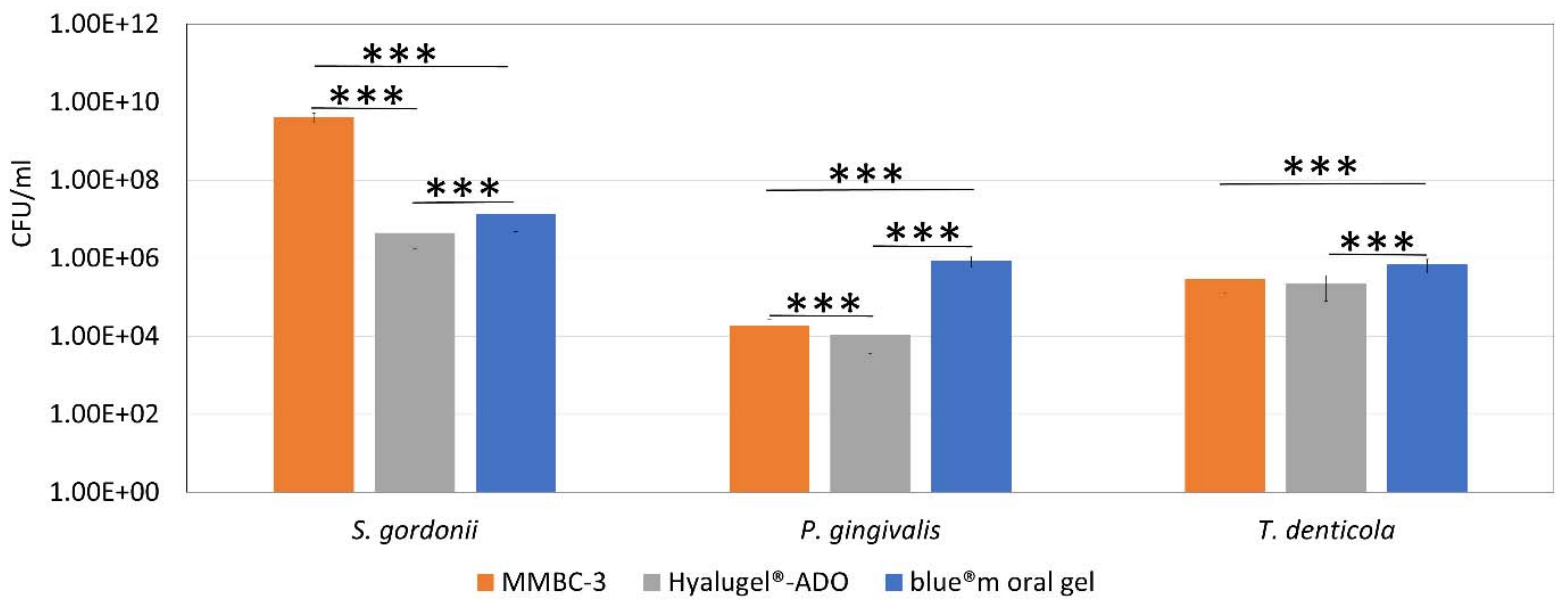

Figure 3 
bioRxiv preprint doi: https://doi.org/10.1101/2020.09.08.287391; this version posted September 8, 2020. The copyright holder for this preprint (which was not certified by peer review) is the author/funder, who has granted bioRxiv a license to display the preprint in perpetuity. It is made available under aCC-BY-NC-ND 4.0 International license.

A

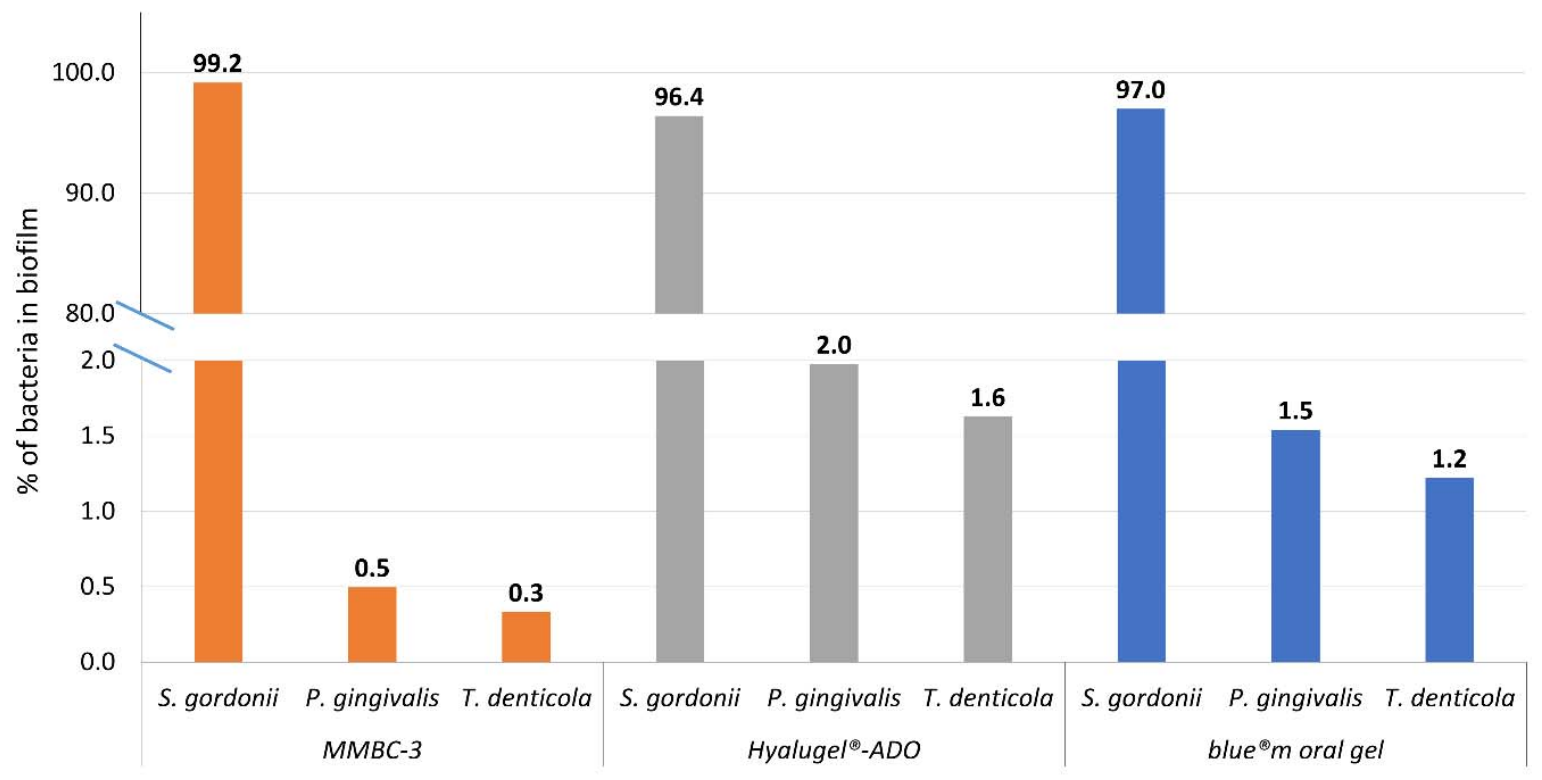

B

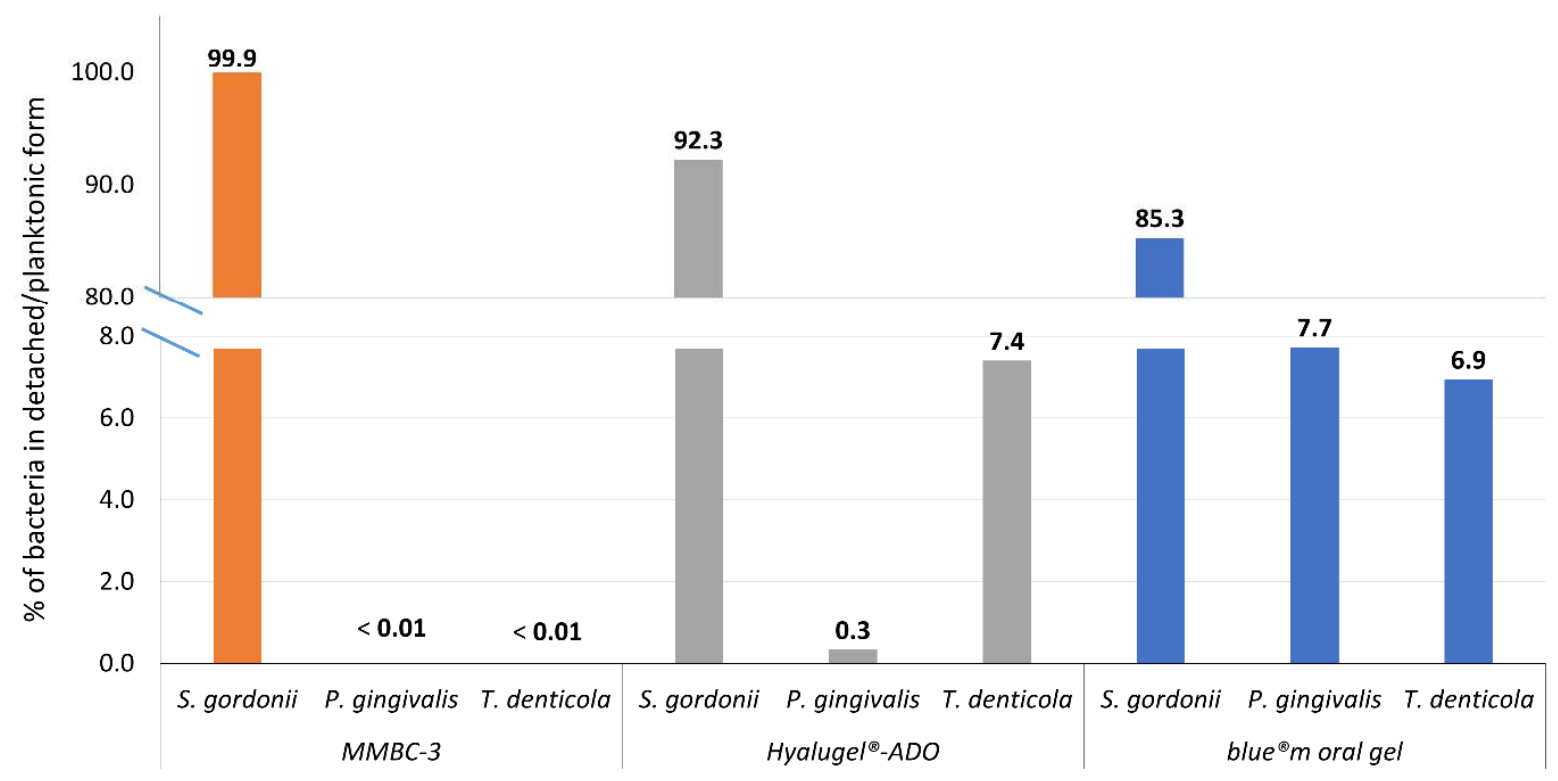

Figure 4 